\title{
Two-Year Recurrence After First-Ever Stroke in a General Population of 1.4 Million Japanese Patients - The Shiga Stroke and Heart Attack Registry Study -
}

\author{
Naoyuki Takashima, MD; Hisatomi Arima, MD; Yoshikuni Kita, PhD; \\ Takako Fujii; Sachiko Tanaka-Mizuno, PhD; Satoshi Shitara, MD; \\ Akihiro Kitamura, MD; Katsuyuki Miura, MD; Kazuhiko Nozaki, MD \\ on behalf of the Shiga Stroke and Heart Attack Registry Group
}

\begin{abstract}
Background: Despite many effective strategies for the prevention of recurrent stroke, individuals who survive an initial stroke have been shown to be at high risk of recurrent stroke. The aim of this study was to investigate the current status of stroke recurrence after first-ever stroke using a population-based stroke registry in Japan.
\end{abstract}

\begin{abstract}
Methods and Results: As part of the Shiga Stroke and Heart Attack Registry, the Shiga Stroke Registry is an ongoing populationbased stroke registry study that covers approximately 1.4 million residents of Shiga Prefecture, Japan. A total of 1,883 first-ever stroke survivors at 28 days was registered in 2011 and followed-up until the end of 2013. Recurrence was defined as any type of stroke after 28 days from the onset of an index event. Two-year cumulative recurrence rates were estimated using cumulative incidence function methods. Over a mean 2.1-year follow-up period, 120 patients experienced recurrent stroke and 389 patients died without recurrence. The 2-year cumulative recurrence rate was higher in patients with index ischemic stroke $(6.8 \%)$ than in those with index hemorrhagic stroke (3.8\%).
\end{abstract}

Conclusions: Two-year cumulative recurrence rate after first-ever stroke remained high, particularly among patients with ischemic stroke, in the present population-based registry study in a real-world setting in Japan. Further intensive secondary prevention strategies are required for these high-risk individuals.

Key Words: Asian; Population studies; Recurrence event; Stroke

\begin{abstract}
A ge-standardized stroke mortality in Japan has decreased rapidly over the past 5 decades. ${ }^{1}$ However, stroke remains one of the leading causes of death ${ }^{2}$ and disability. ${ }^{3}$ Furthermore, despite a number of effective strategies for the secondary prevention of stroke, individuals who survive an initial stroke have been shown to be at very high risk of recurrent stroke. ${ }^{4}$ Studies in several countries have indicated that the risk of stroke recurrence has decreased over past decades, ${ }^{\mathbf{5}, \mathbf{6}}$ with one recent study from Ireland reporting a 2-year recurrence rate of approximately $11 \% .^{7}$ However, only limited up-to-date information is available regarding stroke recurrence, particularly typespecific ischemic stroke, from population-based studies in East Asian countries, where there is a higher prevalence of hemorrhagic stroke and lacunar infarction. ${ }^{8}$
\end{abstract}

As part of the Shiga Stroke and Heart Attack Registry (SSHR), the Shiga Stroke Registry is an ongoing comprehensive, population-based, large-scale stroke registry study in Japan. We have previously reported the incidence rate ${ }^{9}$ and 2-year survival rate ${ }^{10}$ of stroke using data from the registry. The aim of the present study was to investigate current cumulative stroke recurrence after first-ever stroke using the population-based stroke registry in Shiga Prefecture, Japan.

\section{Methods}

Study Design

The methodology of the Shiga Stroke Registry Study has been described in detail elsewhere. ${ }^{9,10}$ Briefly, as part of the

Received January 23, 2020; revised manuscript received March 19, 2020; accepted March 25, 2020; J-STAGE Advance Publication released online April 29, 2020 Time for primary review: 37 days

Department of Public Health (N.T., Y.K., K.M.), Department of Neurosurgery (T.F., S.S., K.N.), Department of Medical Statistics (S.T.-M.), Department of Neurology (A.K.), Center for Epidemiologic Research in Asia (K.M., K.N.), Shiga University of Medical Science, Otsu; Department of Public Health, Kindai University Faculty of Medicine, Osaka-Sayama (N.T.); Department of Preventive Medicine and Public Health, Faculty of Medicine, Fukuoka University, Fukuoka (H.A., T.F.); and Tsuruga Nursing University, Tsuruga (Y.K.), Japan

Mailing address: Naoyuki Takashima, MD, PhD, Department of Public Health, Kindai University Faculty of Medicine, 377-2 Ohnohigashi, Osaka-Sayama 589-8511, Japan. E-mail: n.takashima@med.kindai.ac.jp

ISSN-1346-9843 All rights are reserved to the Japanese Circulation Society. For permissions, please e-mail: cj@j-circ.or.jp 


\begin{tabular}{|c|c|c|c|}
\hline & Ischemic stroke & Hemorrhagic stroke & Total stroke \\
\hline Total no. patients & 1,299 & 583 & 1,883 \\
\hline Male sex & $743(57.2)$ & $260(44.6)$ & $1,003(53.3)$ \\
\hline Age (years) & $74.2 \pm 13.2$ & $68.2 \pm 15.1$ & $72.3 \pm 14.1$ \\
\hline \multicolumn{4}{|l|}{ Past history } \\
\hline \multicolumn{4}{|l|}{ Transient ischemic attacks } \\
\hline Yes & $71(5.5)$ & $8(1.4)$ & $79(4.2)$ \\
\hline No & $1,225(94.3)$ & $572(98.1)$ & 1,798 (95.5) \\
\hline Unknown & $3(0.2)$ & $3(0.5)$ & $6(0.3)$ \\
\hline \multicolumn{4}{|l|}{ Atrial fibrillation } \\
\hline Yes & $288(22.2)$ & $38(6.5)$ & $326(17.3)$ \\
\hline No & $1,005(77.4)$ & $540(92.6)$ & $1,546(82.1)$ \\
\hline Unknown & $6(0.5)$ & $5(0.9)$ & $11(0.6)$ \\
\hline \multicolumn{4}{|l|}{ Myocardial infarction } \\
\hline Yes & $79(6.1)$ & $27(4.6)$ & $107(5.7)$ \\
\hline No & $1,218(93.8)$ & $554(95.0)$ & $1,772(94.1)$ \\
\hline Unknown & $2(0.2)$ & $2(0.3)$ & $4(0.2)$ \\
\hline \multicolumn{4}{|l|}{ Hypertension } \\
\hline Yes & $915(70.4)$ & 419 (71.9) & 1,335 (70.9) \\
\hline No & $379(29.2)$ & $160(27.4)$ & $539(28.6)$ \\
\hline Unknown & $5(0.4)$ & $4(0.7)$ & $9(0.5)$ \\
\hline \multicolumn{4}{|l|}{ Diabetes } \\
\hline Yes & $360(27.7)$ & $114(19.6)$ & $474(25.2)$ \\
\hline No & $933(71.8)$ & 466 (79.9) & $1,400(74.3)$ \\
\hline Unknown & $6(0.5)$ & $3(0.5)$ & $9(0.5)$ \\
\hline \multicolumn{4}{|l|}{ Dyslipidemia } \\
\hline Yes & $510(39.3)$ & $158(27.1)$ & $668(35.5)$ \\
\hline No & $751(57.8)$ & $377(64.7)$ & $1,129(60.0)$ \\
\hline Unknown & $38(2.9)$ & $48(8.2)$ & $86(4.6)$ \\
\hline \multicolumn{4}{|l|}{ Smoking status } \\
\hline Non-smoker & $737(56.7)$ & $352(60.4)$ & $1,090(57.9)$ \\
\hline Past smoker & $152(11.7)$ & $57(9.8)$ & $209(11.1)$ \\
\hline Current smoker & $309(23.8)$ & $129(22.1)$ & $438(23.3)$ \\
\hline Unknown & $101(7.8)$ & $45(7.7)$ & $146(7.8)$ \\
\hline \multicolumn{4}{|l|}{ Drinking status } \\
\hline Non-drinker & $645(49.7)$ & $296(50.8)$ & $941(50.0)$ \\
\hline Past drinker & $21(1.6)$ & $7(1.2)$ & $28(1.5)$ \\
\hline Current drinker & $468(36.0)$ & $213(36.5)$ & $682(36.2)$ \\
\hline Unknown & $165(12.7)$ & $67(11.5)$ & $232(12.3)$ \\
\hline \multicolumn{4}{|l|}{ Index stroke subtype } \\
\hline Intracerebral hemorrhage & & $447(76.5)$ & $447(23.7)$ \\
\hline Subarachnoid hemorrhage & & $136(23.3)$ & $136(7.2)$ \\
\hline Lacunar infarction & $347(26.7)$ & & $347(18.4)$ \\
\hline Large artery infarction & $413(31.8)$ & & $413(21.9)$ \\
\hline Cardioembolic infarction & 307 (23.6) & & 307 (16.3) \\
\hline Other/undetermined & $232(17.9)$ & & $232(12.3)$ \\
\hline
\end{tabular}

Unless indicated otherwise, data are given as $n(\%)$ or the mean \pm SD.

SSHR, the Shiga Stroke Registry is an ongoing multicenter, population-based registry study of stroke designed to build a complete information system on acute ischemic and nontraumatic hemorrhagic stroke management in Shiga Prefecture, Japan. Shiga Prefecture is located in the central part of Honshu Island. Based on the 2011 census, the population of Shiga Prefecture is 1,400,745 (689,859 men, 710,866 women).
Diagnosis of index stroke was defined as a sudden onset of focal neurological deficits persisting for more than $24 \mathrm{~h}$, according to the World Health Organization (WHO) Multinational Monitoring of Trends and Determinants in Cardiovascular Disease (MONICA) Project. ${ }^{11}$ All registered cases were adjudicated by more than 2 independent investigators. Index stroke was classified as ischemic stroke, hemorrhagic stroke (intracerebral hemorrhage and sub- 


\begin{tabular}{|c|c|c|c|c|c|c|}
\hline & \multicolumn{3}{|c|}{ At 1 year } & \multicolumn{3}{|c|}{ At 2 years } \\
\hline & $\begin{array}{l}\text { No. cases } \\
\text { recurrence* }\end{array}$ & $\begin{array}{l}\text { Cumulative } \\
\text { recurrence } \\
\text { rate (\%) }\end{array}$ & $95 \% \mathrm{Cl}$ & $\begin{array}{l}\text { No. cases } \\
\text { recurrence* }\end{array}$ & $\begin{array}{c}\text { Cumulative } \\
\text { recurrence } \\
\text { rate (\%) }\end{array}$ & $95 \% \mathrm{Cl}$ \\
\hline Total stroke & $60(45 / 15)$ & 3.2 & $2.5-4.1$ & $110(81 / 29)$ & 5.8 & $4.8-7.0$ \\
\hline Men & $32(25 / 7)$ & 3.2 & $2.2-4.4$ & $62(50 / 12)$ & 6.2 & $4.8-7.8$ \\
\hline Women & $28(20 / 8)$ & 3.2 & $2.2-4.5$ & $48(31 / 17)$ & 5.5 & $4.1-7.1$ \\
\hline \multicolumn{7}{|l|}{ Age (years) } \\
\hline$<70$ & $17(14 / 3)$ & 2.3 & $1.4-3.6$ & $32(25 / 7)$ & 4.3 & $3.0-6.0$ \\
\hline$\geq 70$ & $43(31 / 12)$ & 3.8 & $2.8-5.0$ & 78 (56/22) & 6.8 & $5.5-8.4$ \\
\hline Ischemic stroke & $45(41 / 4)$ & 3.5 & $2.6-4.6$ & $88(76 / 12)$ & 6.8 & $5.5-8.2$ \\
\hline \multicolumn{7}{|l|}{ Ischemic stroke subtype } \\
\hline Lacunar infarction & $11(10 / 1)$ & 3.2 & $1.7-5.4$ & $21(18 / 3)$ & 6.1 & $3.9-8.9$ \\
\hline Large artery infarction & $18(15 / 3)$ & 4.4 & $2.7-6.6$ & $39(34 / 5)$ & 9.4 & $6.9-12.5$ \\
\hline Cardioembolic infarction & $10(10 / 0)$ & 3.3 & $1.7-5.7$ & $19(15 / 4)$ & 6.2 & $3.9-9.3$ \\
\hline Other/undermined & $6(6 / 0)$ & 2.6 & $1.1-5.3$ & $9(9 / 0)$ & 3.9 & $1.9-7.0$ \\
\hline Hemorrhagic stroke & $15(4 / 11)$ & 2.6 & $1.5-4.1$ & $22(5 / 17)$ & 3.8 & $2.4-5.6$ \\
\hline
\end{tabular}

*Data show the number of cases of recurrence of total stroke (ischemic stroke/hemorrhagic stroke). $\mathrm{Cl}$, confidence interval.

arachnoid hemorrhage), and undetermined type of stroke. Based on the criteria for subtypes of stroke in the Trial of Org 10172 in Acute Stroke Treatment (TOAST) study, ${ }^{12}$ ischemic stroke was further divided into lacunar infarction, large artery infarction, cardioembolic infarction, and undetermined type of ischemic stroke.

In all, 2,176 patients with first-ever stroke with onset dates ranging from 1 January to 31 December 2011 were followed-up until December 2013. After excluding 293 patients who died within 28 days of the index stroke, 1,883 participants were included in the present analysis. The SSHR study was approved by the Institutional Review Board of Shiga University of Medical Science (Reference no. 23-186-1) and followed the Declaration of Helsinki and the ethical standards of the responsible committee on human experimentation.

\section{Clinical Features and Medical Histories}

Information on medical history, including transient ischemic attack (TIA), atrial fibrillation, myocardial infarction (MI), hypertension, diabetes, dyslipidemia, and smoking and drinking status, was extracted from the medical records. Atrial fibrillation was defined as a history of atrial fibrillation and/or clinical diagnosis based on electrocardiogram (ECG) and/or ECG monitoring during hospitalization. Hypertension was defined as systolic blood pressure $\geq 140 \mathrm{mmHg}$, diastolic blood pressure $\geq 90 \mathrm{mmHg}$, using antihypertensive medication, and/or a history of hypertension. Diabetes was defined as casual blood glucose $\geq 11.1 \mathrm{mmol} / \mathrm{L}$, the use of antidiabetic medication, and/or a history of diabetes. Dyslipidemia was defined as total cholesterol $\geq 5.69 \mathrm{mmol} / \mathrm{L}$, low-density lipoprotein cholesterol $\geq 4.14 \mathrm{mmol} / \mathrm{L}$, medication for dyslipidemia, and/or a history of dyslipidemia. Smoking status was categorized as non-smoker, past smoker, and current smoker. Alcohol consumption was categorized into non-drinker, past drinker, and current drinker.

\section{Follow-up Survey}

All patients with first-ever stroke who were alive at 28 days after the index stroke were followed-up until end of 2013 using the population-based Shiga Stroke Registry and death certificate information of all deceased residents in the region, with the permission of the Japanese Ministry of Health, Labour and Welfare. The definition of recurrent stroke was the same as for the index stroke. In the Registry, a stroke recurring within 28 days of the index stroke is considered part of the original episode, as per the WHO MONICA Project. ${ }^{11}$ The main outcome of the present study was the recurrence of any stroke, which was defined as a sudden onset of focal neurological deficits persisting for more than $24 \mathrm{~h},{ }^{11}$ from 28 days after the onset of an index event.

\section{Statistical Analysis}

Cumulative recurrence rates of first-ever stroke were estimated using cumulative incidence function methods, considering death as a competing risk, and compared using Gray's test. ${ }^{13}$ Two-sided $\mathrm{P}<0.05$ was consider significant. All analyses were performed using SAS 9.4 (SAS Institute, Cary, NC, USA).

\section{Results}

The baseline characteristics of first-ever stroke survivors at 28 days are given according to the type of index stroke in Table 1. The mean age of patients with an index ischemic stroke was 74.2 years, and 68.2 years for patients with index hemorrhagic stroke. The prevalence rates of a history of TIA, atrial fibrillation, and MI for all stroke patients were $4.2 \%, 17.3 \%$, and $5.7 \%$, respectively.

During the follow-up period (mean 2.1 years), 120 patients experienced recurrent stroke after 28 days from the onset of an index events and 389 patients died without recurrence. Cumulative recurrence rates of all patients with stroke and those in subgroups according to type of index stroke and sex are given in Table 2. Cumulative recurrence rates after first-ever stroke were $3.2 \%(3.2 \%$ in men, $3.2 \%$ in women $)$ at 1 year and $5.8 \%(6.2 \%$ in men, $5.5 \%$ in women $)$ at 2 years. The cumulative recurrence rates after first-ever stroke were $4.3 \%$ in the younger (age $<70$ years) group and $6.8 \%$ in the 
A Cumulative recurrence rate after first-ever stroke by type of index stroke

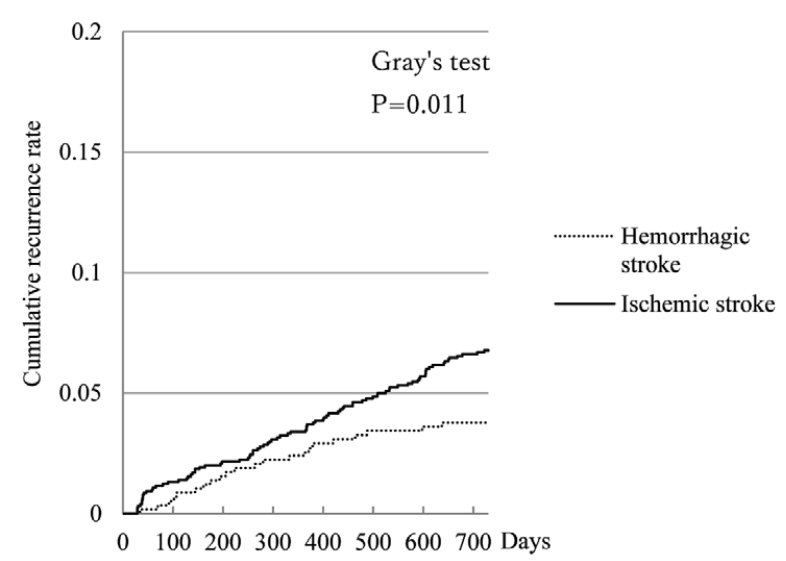

B Cumulative recurrence after first-ever stroke by type of index ischemic stroke

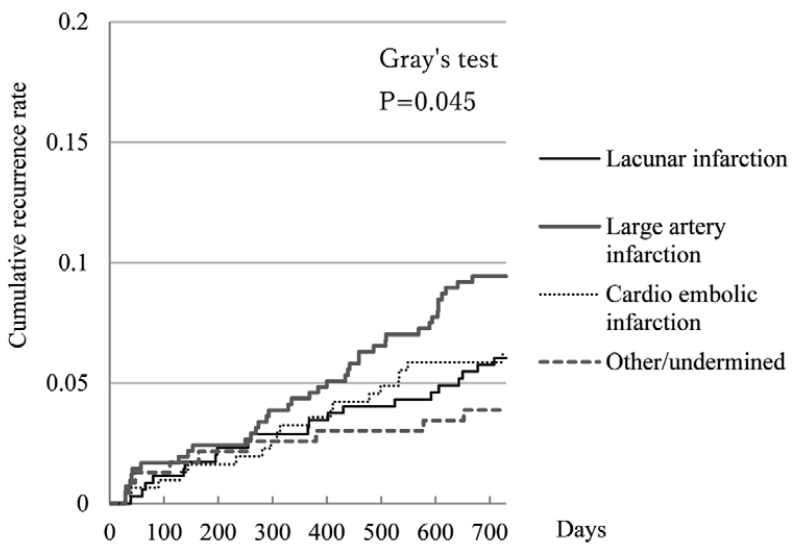

C Cumulative recurrence after first-ever stroke, by sex

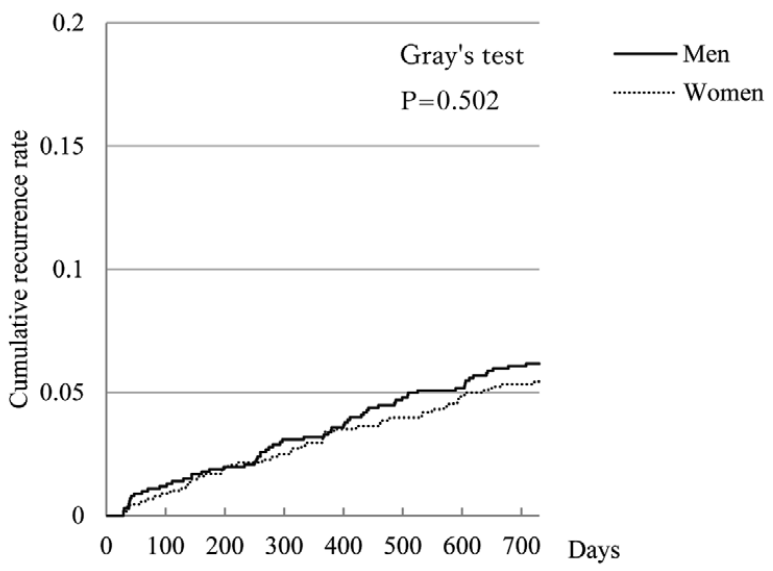

Figure. Two-year recurrence rate curves after first-ever stroke by $(\mathbf{A})$ index stroke subtype, $(\mathbf{B})$ index ischemic stroke subtype, and $(\mathbf{C})$ sex. Cumulative recurrence rates were estimated using cumulative incidence function methods, considering death as a competing risk, and compared using Gray's test.

older (age $\geq 70$ years) group. The cumulative recurrence rates at 2 years for patients with index ischemic stroke and index hemorrhagic stroke were $6.8 \%$ and $3.8 \%$, respectively. The cumulative recurrence rates at 2 years for patients with index lacunar infarction, large artery infarction, and cardioembolic infarction were $6.1 \%, 9.4 \%$, and $6.2 \%$, respectively. The cumulative incidence of recurrent stroke is shown according to type of index stroke and sex in Figure. Higher recurrence rates were observed in individuals with index ischemic stroke, especially those with large artery infarction, than in those with index hemorrhagic stroke. The incidence rates of recurrent stroke were similar between men and women.

\section{Discussion}

The present comprehensive population-based stroke registry study in Japan demonstrated the current status of 2-year recurrence after 28 days from the onset of first-ever stroke in a real-world setting in Japan. Cumulative recurrence rates for total stroke after first-ever stroke were 3.2\% at 1 year and $5.8 \%$ at 2 year $(6.2 \%$ for patients with ischemic stroke, $3.8 \%$ for those with hemorrhagic stroke). Higher risks of recurrence were observed among patients with ischemic stroke and those with a history of TIA.

To the best of our knowledge, this is the first study to report the 2-year cumulative recurrence rates of total stroke, ischemic stroke and its subtypes, and hemorrhagic stroke based on a recent comprehensive, population-based, largescale registry in Asian countries. The definition of stroke recurrence was heterogeneous across different studies. According to a recent meta-analysis, the annual recurrence rate of stroke is $4.3 \%$, but rates are higher in randomized control trials $(4.6 \%)$ or hospital-based studies $(4.5 \%)$ than in community-based studies $(2.6 \%) .{ }^{14}$ That meta-analysis did not find a decreasing trend in stroke recurrence, ${ }^{\mathbf{1 4}}$ 
although several longitudinal studies have reported decreasing trends in the recurrence of total or ischemic stroke.,5,6,15-17 Previous studies showed that the rate of stroke recurrence after first-ever stroke was $8.0 \%$ and $13.2 \%$ in the UK ${ }^{\mathbf{1 8 , 1 9}}$ and $16.0 \%$ in Australia. ${ }^{20}$ In Japan, the recurrence rate after first-ever stroke at 1 year was reported to range from $6.5 \%$ to $12.8 \%, 21,22$ however, these studies were conducted $10-30$ years ago. Recent studies have demonstrated lower recurrence rates at 1 year (excluding recurrence within 1 month after the onset of index stroke) than those reported in older studies (4.6\% in Iran, ${ }^{23} 6 \%$ in Sweden $)$. Recent hospitalbased studies ${ }^{24}$ or clinical trials ${ }^{\mathbf{2 5 , 2 6}}$ conducted in Japan also reported an annual recurrence rate of stroke in the range $2.3-3.7 \%$. The present study, which found a recurrence rate of $3.2 \%$ at 1 year, confirms the findings of other recent studies and indicates that the stroke recurrence rate may have decreased over recent decades in Japan, as in some other countries.

In the present study, higher recurrence rates were observed in patients with ischemic stroke (especially large artery infarction) than in those with hemorrhagic stroke. Previous studies have also reported a higher risk of recurrence among patients with ischemic stroke. ${ }^{7,22,23}$ Among the subtypes of ischemic stroke, large artery infarction has been shown to be associated with a higher risk of recurrence than other subtypes. ${ }^{27}$

In Asian countries, the proportion of large artery infarction among patients with ischemic stroke has increased over recent decades, and it is now the most common subtype of ischemic stroke. ${ }^{28}$ Moreover, patients with stroke events are at a high risk of recurrence of not only of the same type of event, but also other types of vascular events. ${ }^{29}$ These findings emphasize the importance of secondary prevention for patients with ischemic stroke, especially for those with prior large artery infarction. Moreover, this type of infarction may be caused by atherosclerosis, and assessment and control of multiple risk factors may be needed. ${ }^{30}$

This study has several limitations. First, patients who moved out of Shiga Prefecture after the onset of index stroke were lost to follow-up because information on death and recurrence was collected only for residents of Shiga Prefecture. Therefore, the recurrence rates after stroke may have been underestimated. However, reports on internal migration derived from Basic Resident Registers showed that only $3.6 \%$ of residents moved out of Shiga Prefecture during the 2-year study period. Another limitation of the study is a lack of information on medications after discharge, which make it difficult to assess long-term adherence to secondary prevention strategies.

\section{Conclusions}

In this population-based stroke registry study in a realworld setting in Japan, the 2-year cumulative recurrence rate after first-ever stroke remained high, particularly among patients with ischemic stroke. More intensive secondary prevention strategies are required for these high-risk individuals.

\section{Acknowledgments}

The authors thank all the investigators, participating hospitals, study staff at the Shiga Stroke Data Center, Shiga Medical Association, Shiga Prefecture Hospital Association, Biwako Brain \& Heart Attack Consortium (BIWA-BHAC), Department of Public Health Care and Welfare, and Shiga Prefecture government. The authors also thank
Analisa Avila, of Edanz Group (www.edanzediting.com/ac), for English language editing a draft of this manuscript.

\section{Sources of Funding}

Shiga Stroke and Heart Attack Registry and this work are supported by Shiga Prefecture and the Japan Agency for Medical Research and Development (AMED).

\section{Disclosures}

The authors declare that there are no conflicts of interest.

\section{References}

1. Ueshima H. Explanation for the Japanese paradox: Prevention of increase in coronary heart disease and reduction in stroke. $J$ Atheroscler Thromb 2007; 14: 278-286.

2. Ministry of Health, Labour and Welfare. Results of vital statistics, 2014. http://www.mhlw.go.jp/toukei/saikin/hw/jinkou/kakutei14/ index.html (accessed April 20, 2019).

3. Ministry of Health, Labour and Welfare. The results of comprehensive survey of living conditions, 2013. http://www.mhlw. go.jp/toukei/saikin/hw/k-tyosa/k-tyosa13/index.html (accessed April 20, 2019).

4. Mohan KM, Wolfe CD, Rudd AG, Heuschmann PU, KolominskyRabas PL, Grieve AP. Risk and cumulative risk of stroke recurrence: A systematic review and meta-analysis. Stroke 2011; 42: $1489-1494$.

5. Pennlert J, Eriksson M, Carlberg B, Wiklund PG. Long-term risk and predictors of recurrent stroke beyond the acute phase. Stroke 2014; 45: 1839-1841.

6. Lewsey J, Jhund PS, Gillies M, Chalmers JW, Redpath A, Briggs A, et al. Temporal trends in hospitalisation for stroke recurrence following incident hospitalisation for stroke in Scotland. BMC Med 2010; 8: 23.

7. Callaly E, Ni Chroinin D, Hannon N, Marnane M, Akijian L, Sheehan O, et al. Rates, predictors, and outcomes of early and late recurrence after stroke: The North Dublin Population Stroke Study. Stroke 2016; 47: 244-246.

8. Ueshima H, Sekikawa A, Miura K, Turin TC, Takashima N, Kita $\mathrm{Y}$, et al. Cardiovascular disease and risk factors in Asia: A selected review. Circulation 2008; 118: 2702-2709.

9. Takashima N, Arima H, Kita Y, Fujii T, Miyamatsu N, Komori $\mathrm{M}$, et al. Incidence, management and short-term outcome of stroke in a general population of 1.4 million Japanese: Shiga Stroke Registry. Circ J 2017; 81: 1636-1646.

10. Takashima N, Arima H, Kita Y, Fujii T, Miyamatsu N, Komori $\mathrm{M}$, et al. Two-year survival after first-ever stroke in a general population of 1.4 million Japanese: Shiga Stroke Registry. Circ J 2018; 82: 2549-2556.

11. Tunstall-Pedoe $\mathrm{H}$. Monitoring trends in cardiovascular disease and risk factors: The WHO "Monica" project. WHO Chron 1985; 39: $3-5$.

12. Adams HP Jr, Bendixen BH, Kappelle LJ, Biller J, Love BB, Gordon DL, et al. Classification of subtype of acute ischemic stroke: Definitions for use in a multicenter clinical trial. TOAST. Trial of Org 10172 in Acute Stroke Treatment. Stroke 1993; 24: $35-41$

13. Gray RJ. A class of K-sample tests for comparing the cumulative incidence of a competing risk. Ann Statist 1988; 16: 1141-1154.

14. Boulanger M, Bejot Y, Rothwell PM, Touze E. Long-term risk of myocardial infarction compared to recurrent stroke after transient ischemic attack and ischemic stroke: Systematic review and meta-analysis. J Am Heart Assoc 2018; 7: pii: e007267.

15. Santalucia P, Baviera M, Cortesi L, Tettamanti M, Marzona I, Nobili A, et al. Epidemiologic trends in hospitalized ischemic stroke from 2002 to 2010: Results from a large Italian population-based study. J Stroke Cerebrovasc Dis 2015; 24: 1917-1923.

16. Lee $\mathrm{M}, \mathrm{Wu} \mathrm{YL}$, Ovbiagele B. Trends in incident and recurrent rates of first-ever ischemic stroke in Taiwan between 2000 and 2011. J Stroke 2016; 18: 60-65.

17. Bergstrom L, Irewall AL, Soderstrom L, Ogren J, Laurell K, Mooe T. One-year incidence, time trends, and predictors of recurrent ischemic stroke in Sweden from 1998 to 2010: An observational study. Stroke 2017; 48: 2046-2051.

18. Hillen T, Coshall C, Tilling K, Rudd AG, McGovern R, Wolfe $\mathrm{CD}$. Cause of stroke recurrence is multifactorial: Patterns, risk factors, and outcomes of stroke recurrence in the South London Stroke Register. Stroke 2003; 34: 1457-1463. 
19. Burn J, Dennis M, Bamford J, Sandercock P, Wade D, Warlow C. Long-term risk of recurrent stroke after a first-ever stroke: The Oxfordshire Community Stroke Project. Stroke 1994; 25: 333 337.

20. Hardie K, Hankey GJ, Jamrozik K, Broadhurst RJ, Anderson C. Ten-year risk of first recurrent stroke and disability after firstever stroke in the Perth Community Stroke Study. Stroke 2004; 35: $731-735$.

21. Hata J, Tanizaki Y, Kiyohara Y, Kato I, Kubo M, Tanaka K, et al. Ten year recurrence after first ever stroke in a Japanese community: The Hisayama study. J Neurol Neurosurg Psychiatry 2005; 76: $368-372$

22. Yokota C, Minematsu K, Hasegawa Y, Yamaguchi T. Longterm prognosis, by stroke subtypes, after a first-ever stroke: A hospital-based study over a 20 -year period. Cerebrovasc Dis 2004; 18: $111-116$

23. Salehi M, Amiri A, Thrift AG, Kapral MK, Sposato L, Behrouz $\mathrm{R}$, et al. Five-year recurrence rate and the predictors following stroke in the Mashhad Stroke Incidence Study: A populationbased cohort study of stroke in the Middle East. Neuroepidemiology 2018; 50: 18-22.

24. Goto S, Ikeda Y, Shimada K, Uchiyama S, Origasa H, Kobayashi H. One-year cardiovascular event rates in Japanese outpatients with myocardial infarction, stroke, and atrial fibrillation: Results From the Japan Thrombosis Registry for Atrial Fibrillation,
Coronary, or Cerebrovascular Events (J-TRACE). Circ J 2011; 75: $2598-2604$

25. Shinohara Y, Katayama Y, Uchiyama S, Yamaguchi T, Handa S, Matsuoka K, et al. Cilostazol for prevention of secondary stroke (CSPS 2): An aspirin-controlled, double-blind, randomised noninferiority trial. Lancet Neurol 2010; 9: 959-968.

26. Kitagawa K, Yamamoto Y, Arima H, Maeda T, Sunami N, Kanzawa T, et al. Effect of standard vs intensive blood pressure control on the risk of recurrent stroke: A randomized clinical trial and meta-analysis. JAMA Neurol 2019; 76: 1309-1318.

27. Kauw F, Takx RAP, de Jong H, Velthuis BK, Kappelle LJ, Dankbaar JW. Clinical and imaging predictors of recurrent ischemic stroke: A systematic review and meta-analysis. Cerebrovasc Dis 2018; 45: 279-287.

28. Ornello R, Degan D, Tiseo C, Di Carmine C, Perciballi L, Pistoia F, et al. Distribution and temporal trends from 1993 to 2015 of ischemic stroke subtypes: A systematic review and meta-analysis. Stroke 2018; 49: 814-819.

29. Arima H, Tzourio C, Butcher K, Anderson C, Bousser MG, Lees $\mathrm{KR}$, et al. Prior events predict cerebrovascular and coronary outcomes in the PROGRESS trial. Stroke 2006; 37: 1497-1502.

30. Hosomi N, Nagai Y, Kohriyama T, Ohtsuki T, Aoki S, Nezu T, et al. The Japan Statin Treatment Against Recurrent Stroke (J-STARS): A multicenter, randomized, open-label, parallelgroup study. EBioMedicine 2015; 2: 1071-1078. 